\title{
Vulnerability to interpretation bias in overweight children
}

Citation for published version (APA):

Jansen, A. T. M., Smeets, T., Boon, B., Nederkoorn, C., Roefs, A. J., \& Mulkens, S. (2007). Vulnerability to interpretation bias in overweight children. Psychology \& Health, 22(5), 561-574.

https://doi.org/10.1080/14768320600941012

Document status and date:

Published: 01/01/2007

DOI:

10.1080/14768320600941012

Document Version:

Publisher's PDF, also known as Version of record

Document license:

Taverne

Please check the document version of this publication:

- A submitted manuscript is the version of the article upon submission and before peer-review. There can be important differences between the submitted version and the official published version of record.

People interested in the research are advised to contact the author for the final version of the publication, or visit the DOI to the publisher's website.

- The final author version and the galley proof are versions of the publication after peer review.

- The final published version features the final layout of the paper including the volume, issue and page numbers.

Link to publication

\footnotetext{
General rights rights.

- You may freely distribute the URL identifying the publication in the public portal. please follow below link for the End User Agreement:

www.umlib.nl/taverne-license

Take down policy

If you believe that this document breaches copyright please contact us at:

repository@maastrichtuniversity.nl

providing details and we will investigate your claim.
}

Copyright and moral rights for the publications made accessible in the public portal are retained by the authors and/or other copyright owners and it is a condition of accessing publications that users recognise and abide by the legal requirements associated with these

- Users may download and print one copy of any publication from the public portal for the purpose of private study or research.

- You may not further distribute the material or use it for any profit-making activity or commercial gain

If the publication is distributed under the terms of Article $25 \mathrm{fa}$ of the Dutch Copyright Act, indicated by the "Taverne" license above, 


\section{Vulnerability to interpretation bias in overweight children}

\section{Anita Jansen, Tom Smeets, Brigitte Boon , Chantal Nederkoorn , Anne Roefs} \& Sandra Mulkens

To cite this article: Anita Jansen, Tom Smeets, Brigitte Boon, Chantal Nederkoorn, Anne Roefs \& Sandra Mulkens (2007) Vulnerability to interpretation bias in overweight children, Psychology and Health, 22:5, 561-574, DOI: 10.1080/14768320600941012

To link to this article: https://doi.org/10.1080/14768320600941012

册 Published online: 11 Jun 2007.

Submit your article to this journal $₫$

III Article views: 193

Q View related articles $\longleftarrow$

Citing articles: 1 View citing articles ¿ 


\title{
Vulnerability to interpretation bias in overweight children
}

\author{
ANITA JANSEN, TOM SMEETS, BRIGITTE BOON, \\ CHANTAL NEDERKOORN, ANNE ROEFS, \& \\ SANDRA MULKENS
}

Faculty of Psychology, Department of Experimental Psychology, Maastricht University,
The Netherlands

(Received 19 February 2004; in final form 6 Fuly 2006)

\begin{abstract}
Obese children are often liable to weight-related teasing, and in earlier studies this childhood teasing has been found to predict body dissatisfaction. Cognitive theory postulates that negative experiences are the source of interpretation biases, implicating that weight-related teasing might make obese children vulnerable to shape- and weightrelated interpretation biases. In the present study, it was tested whether young overweight children show interpretation biases related to body weight/shape and self-esteem. A Situation Interpretation Test (SIT) was used to find out whether overweight children $(n=20)$ interpret neutral and negative ambiguous situations more often in terms of their concerns about body weight/shape and self-esteem than healthy controls $(n=16)$. The data show that 8- to 12-year-old overweight children indeed show interpretation biases, that is, they were more likely to endorse negative appearance and selfesteem-related interpretations of a neutral or negative event than normal-weight children. Also, the perceived threat value of these events was higher in the overweight group. Interpretation biases like this might increase and maintain body dissatisfaction and psychological distress. It is therefore argued that the vulnerability to the development of an interpretation bias emphasises the need to use cognitive strategies that tackle these biases in the treatment of overweight children.
\end{abstract}

Keywords: Interpretation bias, childhood obesity, self-esteem, cognitive theory, information processing

Correspondence: Anita Jansen, Faculty of Psychology, Department of Experimental Psychology, Maastricht University, P.O. Box 616, 6200 MD Maastricht, The Netherlands. E-mail: A.Jansen@psychology.unimaas.nl 


\section{Introduction}

Obesity is a major health problem and its prevalence is rising. The risk of growing into an obese adult is significantly higher for overweight children than for their lean counterparts and increases with age (Dietz, 1995; Pierce \& Wardle, 1997), implying that for people becoming obese at an early age the prevention of adult obesity should start close to the onset, for example by tackling overweight early in childhood.

Whereas obese adults hardly ever profit from treatments that are aimed at reducing their weight, obese children do better. They have some advantages; they have a shorter history of eating and exercise habits and may thus be better able to exchange bad habits for healthier ones. Their height is still increasing and they have more social support, because their parents may help them to maintain the newly learned behaviour, which may further maximise treatment effects (Wilson, 1994). There is, however, still much room for improvement: about $70 \%$ of the children are still overweight 10 years after treatment with behaviour therapy (Epstein, Valoski, Wing, \& McCurley, 1994). Note that behaviour therapy, being the most successful treatment, is currently the treatment of choice for childhood obesity.

Current behavioural treatments usually attempt to change eating and exercise patterns and do not pay much attention to cognitive processes. Recently, it has been suggested that poor treatment effects in obese adults may be partly due to continuing cognitive biases and low self-esteem (e.g., Nauta, Hospers, Jansen, \& Kok, 2000; Nauta, Hospers, Kok, \& Jansen, 2001b; Wilson, 1996). It is argued that treatment effects can be improved by including cognitive interventions that are aimed at the reduction of cognitive errors and the increase of self-esteem and body satisfaction. Indeed, it has been found that obese subjects are characterised by dysfunctional cognitions related to body shape and weight (Nauta, Hospers, \& Jansen, 2001a) and that a cognitive intervention was successful in changing dysfunctional cognitions and low self-esteem in the obese (Nauta et al., 2001a, 2001b). So far, however, little is known about the types of cognitive biases in obesity, whereas it is known that eating disorders such as anorexia and bulimia nervosa are characterised by typical information processing biases such as attention and memory biases (e.g., Cooper, Wells, \& Todd, 2004; Dobson \& Dozois, 2004; Lee \& Shafran, 2004; Williamson, Muller, Reas, \& Thaw, 1999). These biases in information processing are usually pervasive and they may act as maintenance factors in psychopathology. For the modification of behaviour, it is required that this dysfunctional way of information processing changes (Cooper et al., 2004; Lee \& Shafran, 2004; Williamson et al., 1999).

A relevant cognitive bias in eating disorders is the interpretation bias (Cooper, 1997). An interpretation bias reflects a tendency to interpret ambiguous situations in a personally relevant and negative way. Originally the interpretation bias was observed in anxiety patients who were found to interpret ambiguous situations as personally threatening (e.g., Amir, Foa, \& Coles, 1998; Amir, Beard, \& Bower, 2005; Mathews \& Mackintosh, 2000; Taylor \& Alden, 2005). 
In eating disorders, the interpretation bias reflects a negative interpretation of an ambiguous situation in terms of weight and shape. Indeed, an interpretation bias has been found in eating disorders, and weight and shape explanations for ambiguous situations were rated as more upsetting or costly should they occur (Cooper, 1997). The dual overestimation of probability (the chance that negative weight/shape events occur) and costs (being upset if they occur) is supposed to be indicative of the significance of a disorder and has also been described as a judgmental bias (e.g. see Foa, Franklin, Perry, \& Herbert, 1996; Voncken, Bögels, \& de Vries, 2003).

Not only eating disorders are related to increased levels of body dissatisfaction, but also increasing body weight is: it has frequently - but not always - been found that obese people are less satisfied with their bodies than leaner people (Wardle, Waller, \& Fox, 2002). There is some evidence that levels of body dissatisfaction are higher in people who became obese at an early age (Grilo, Wilfley, Brownell, \& Rodin, 1994; Hill \& Williams, 1998). A possible explanation for the link between an early age of onset of obesity and increased body dissatisfaction is an increased number of negative experiences in the obese during growing up: obese children are liable to weight-related teasing, and this childhood teasing has been found to be a powerful predictor of body dissatisfaction (Wardle et al., 2002). Cognitive theory postulates that negative experiences are the source of interpretation biases (Taylor \& Alden, 2005). If overweight children are subjected to more negative weight/shape experiences like teasing, they might estimate the probability of these negative experiences as more likely to occur. Developing such an interpretation bias might maintain severe body dissatisfaction, which is a risk factor for psychological distress and eating disorders (Wardle et al., 2002). If the experienced degree of badness (costs) of negative weight/shape events is also high, the threat value of these events, i.e., the product of the estimated probability and costs, will also be elevated. In anxiety disorders an increased threat value has been found to be associated with increased avoidance behavior (Warren, Zgourides, \& Jones, 1989). Knowing that there is a chance that an event will evoke body shame is one thing, but thinking that this experience will be catastrophic makes it more and more likely that the child will avoid these, mostly social, situations in the future.

In the present study, it is tested whether overweight children interpret ambiguous situations more often in terms of their concerns about body weight/ shape and self-esteem than normal-weight controls. A Situation Interpretation Test (SIT) for overweight children was developed, following Cooper (1997), including a Free Format and a Forced Choice task, as well as subjective probability and cost ratings. It is expected that overweight children will: (a) report more negative weight/shape- and self-esteem-related explanations for ambiguous situations than normal-weight children (hypothesis 1), (b) judge weight/shape and self-esteem to be more likely explanations for events with a negative outcome than normal-weight children (hypothesis 2) and (c) estimate the probability of negative weight/shape events as more likely to occur than normal-weight children and evaluate the costs or degree of badness of these events as higher 
than normal-weight children (hypothesis 3a). They will thus show increased threat perception (hypothesis $3 b$ ).

\section{Method}

\section{Participants}

Advertisements in regional newspapers invited overweight and normal-weight children, aged 8- to 12-years old, to participate in a study called "what young children know and think". By using the Dutch weight-height tables of Roede and van Wieringen (1985), it was possible to determine whether the children that volunteered for participation were either normal-weight or overweight. Participants with a weight equal to or above the 90th percentile representing their height and gender were categorised as overweight, whereas participants with a weight lower than the 90th percentile representing their height and gender were categorised as normal-weight. Twenty overweight (10 boys, 10 girls) and 16 normal-weight (12 boys, 4 girls) children participated in the experiment.

\section{Assessment}

Restrained eating. The intention to restrain food intake was measured by the Restraint Subscale of the Eating Disorder Examination (EDE: Fairburn \& Cooper, 1993) adapted for children (Bryant-Waugh, Cooper, Taylor, \& Lask, 1996) following Braet and collegues (see Decaluwé \& Braet, 1999, 2004; Decaluwé, Braet, \& Fairburn, 2003). The restraint items all concerned the past four weeks: "Over the past four weeks ... (1) have you deliberately been trying to cut down on what you eat, even if you have not managed to do this? ... (2) have there been any days when you have not eaten anything for most $(8 \mathrm{~h})$ of the day? ... (3) have you wanted your tummy to be empty - I mean not to have anything in it at all? ... (4) have you tried not to eat any foods that you like, even if you haven't managed this? And ... (5) have you tried to stick to certain definite rules about your eating; for example, only allowing yourself a certain amount of food, or a certain number of calories, or rules about what you should eat or when you should eat? Each restraint item was scored on a 0-6 intensity or frequency scale and the total restraint score was determined by calculating the mean score, thus ranging from 0 to 6 , with higher scores reflecting a more restrained eating style. Cronbach's alpha of the EDE-restraint subscale in the present study was 0.85 .

Self-perceived competence. Self-perceived competence was measured with the Self-Perception Profile for Children (SPPC: Harter, 1985; Dutch translation: Veerman, Straathof, Treffers, Van den Bergh, \& Ten Brink, 1997). The 36-item SPPC measures perceived competence as part of one's self-esteem and its five subscales are related to five specific domains: scholastic competence, social acceptance, athletic competence, physical appearance and behavioural conduct. A sixth subscale measures global self-worth. Mean subscale scores are presented; 
higher scores indicate increased perceived competence for the scored domain, or higher global self-worth. The mean internal consistency of the Dutch scale is 0.73 and the mean stability (test-retest) is 0.76 (Veerman et al., 1997).

The Situation Interpretation Test (SIT). The SIT included five brief ambiguous situations that might happen to the child (Table I). Two versions of the SIT were used; a free format and a forced-choice format. In the free format SIT the experimenter described a situation, like for example "You are at a birthday party, and you are sitting alone in a corner", and the child was asked to explain that situation. After each situation was described, the child was asked to speak out loud the first response that came to mind. The response was written down literally by the experimenter.

In the forced-choice SIT, the same five situations were presented but now each situation had a negative outcome (Table I). For example, "You are at a birthday party. You are sitting alone. You are thinking something unpleasant. What are you thinking?" The child was given three alternative explanations for the situation, one of which was related to weight/shape (e.g., "I am not good looking"), one of which was related to general self-esteem (e.g., "the other children think I am not able to take part in their game") and one was a nonself-referent response (e.g., "I am thinking that the party is not much fun"). The responses were clearly written on cards and the child was asked what response was most likely to come to mind. A likelihood ranking of the three responses was then made by the child. The responses were scored on a three-point scale, with higher scores reflecting the most likely responses and lower scores reflecting the most unlikely answers.

Finally, the situations with a negative outcome were presented again, and now the child first assessed the probability of occurrence of a negative weight/shape interpretation ("How likely is it that you would be at a birthday party at which you would be sitting alone in a corner thinking that you do not look good?"). The answers were scored on a five-point scale, with higher scores reflecting a larger chance that the event would happen. Second, the child rated the occurrence of a weight/shape-related event on subjective costs ("How bad would this event be for you?"). The answers were scored on a five-point scale, with higher scores reflecting higher costs. In order to increase the understanding of the test, the children were given a sheet with the responses printed after one to five big dots (Table I).

\section{Procedure}

After the explanation of the procedure, the parent or caretaker waited in the waiting room while the child participated in the experiment. The child first completed the SPPC, and then practiced to formulate thoughts in a number of thought exercises. For the practical, the part of the Coping Koala protocol (Barrett, Dadds, \& Rapee, 1996; Muris \& Mayer, 2000) was used, in which children learn to formulate their thoughts. The experimenter made sure that the child understood that his thoughts 


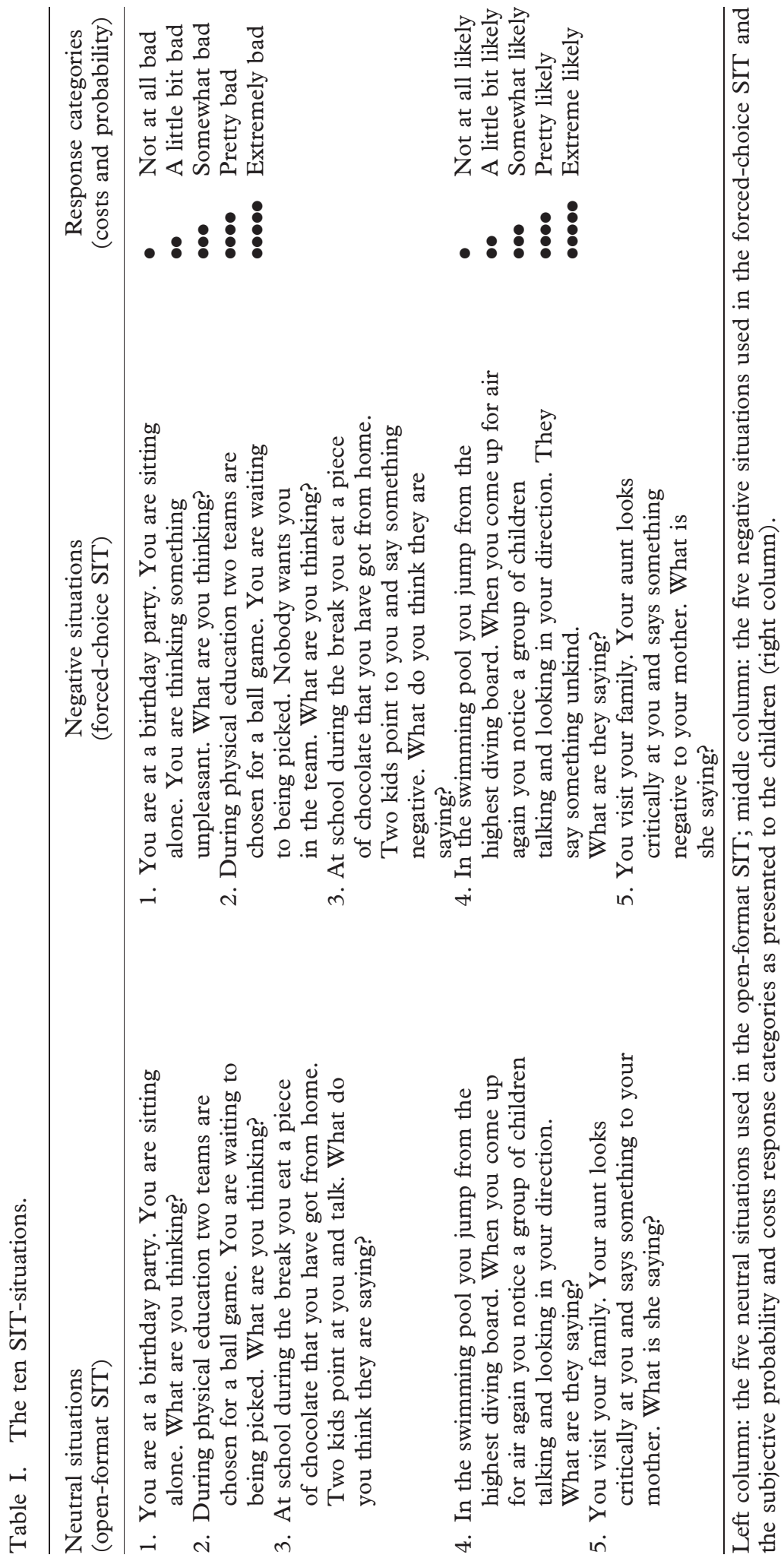


were never wrong: "Since we are interested in your thoughts, it is impossible to make mistakes; please try to be honest about what you think, because that will help us most in understanding the ideas of children." The SIT was done in the order (1) free format, (2) forced choice and (3) ratings of probabilities and costs. After finishing the SIT, the child was interviewed on restrained eating by using the restraint scale of the EDE-Q. Finally, the child's body weight and height were measured. Then the child was given a little present and both the parent and child were thanked for their participation.

\section{Results}

\section{Participant characteristics}

The overweight and normal-weight groups did not differ in age (overweight: $M=9.6, S D=1.1$ versus normal-weight: $M=10.1, S D=1.2, t(34)=1.2, \mathrm{NS}$ ), but, as expected, body mass index (BMI) differed significantly (overweight: $M=24.4, S D=3.0$ versus normal-weight: $M=16.7, S D=1.7, t(34)=9.2$, $p<0.0001)$. The overweight children were significantly more restrained in their eating than the normal-weight children (overweight: $M=1.9, S D=1.0$ versus normal weight: $M=0.3, S D=0.6, t(34)=5.9, p<0.0001)$. For one normalweight participant the self-perceived competence (SPPC) data were incomplete and therefore not included in the analyses. Table II shows that the overweight and normal-weight children did not differ in their self-perceived competence related to scholastic competence and social acceptance. The overweight children were, however, characterised by a significantly lower self-perceived competence than the normal-weight children in three of the six domains: physical appearance, behavioural conduct and global self-worth, and they tended to have a lower self-perceived competence for athletic competence.

Hypothesis 1: Overweight children will report more negative weight/shape- and self- esteem-related explanations for ambiguous situations than normal-weight children. All responses on the open-format SIT were classified into one of five categories: Weight/Shape Negative, Weight/Shape Positive, Self-esteem Negative,

Table II. Self-perceived competence, measured with the Self Perception Profile for Children (Harter, 1985).

\begin{tabular}{lcccc}
\hline & $\begin{array}{c}\text { Overweight } \\
\text { children }(n=20) \\
M(S D)\end{array}$ & $\begin{array}{c}\text { Normal-weight } \\
\text { children }(n=15)\end{array}$ & & \\
$M(S D)$ & $2.9(0.6)$ & 1.3 & 0.205 \\
\hline Scholastic competence & $2.6(0.7)$ & $3.2(0.8)$ & 1.4 & 0.158 \\
Social acceptance & $2.7(0.9)$ & $2.9(0.7)$ & 1.7 & 0.098 \\
Athletic competence & $2.5(0.7)$ & $3.2(0.9)$ & 3.3 & 0.002 \\
Physical appearance & $2.3(0.8)$ & $3.1(0.3)$ & 2.3 & 0.027 \\
Behavioural conduct & $2.7(0.6)$ & $3.4(0.6)$ & 3.1 & 0.004 \\
Global self-worth & $2.7(0.7)$ & &
\end{tabular}


Table III. The open-format SIT: mean number of responses given by the overweight and normalweight children.

\begin{tabular}{lcccccr}
\hline & \multicolumn{7}{c}{ Normal- } \\
& $\begin{array}{c}\text { Overweight }(n=20) \\
M\end{array}$ & $\begin{array}{c}\text { weight }(n=16) \\
M\end{array}$ & \multicolumn{1}{c}{$(S D)$} & $t(34)$ & $p$ \\
\hline Negative self-referent responses & 2.0 & $(1.2)$ & $0.56(0.7)$ & 4.2 & $<0.001$ \\
Weight/shape negative & 1.05 & $(0.9)$ & 0.25 & $(0.6)$ & 3.0 & 0.005 \\
Self-esteem negative & 0.95 & $(0.7)$ & 0.31 & $(0.5)$ & 3.1 & 0.003 \\
Positive self-referent responses & 0.5 & $(0.6)$ & 1.1 & $(0.8)$ & 2.7 & 0.012 \\
Weight/shape positive & 0.25 & $(0.4)$ & 0.25 & $(0.4)$ & 0 & 1.0 \\
Self-esteem positive & 0.25 & $(0.4)$ & 0.88 & $(0.6)$ & 3.5 & 0.001 \\
Non-self-referent responses & 2.5 & $(1.1)$ & 3.3 & $(0.7)$ & 2.6 & 0.015 \\
\hline
\end{tabular}

The self-referent responses are distinguished in positive and negative responses. The positive and negative responses are further distinguished in responses related to weight/shape or self-esteem.

Self-esteem Positive, and thoughts that were unrelated to weight/shape, selfesteem or the self (called the "non-self-referent" category). Two independent raters, each blind to the BMI classification of the participants, classified all responses. The mean inter-rater agreement (Cohen's $\kappa$ ) was 0.88 , which is satisfactory. Table III shows the mean number of responses in each category for overweight and normal-weight children.

The open-format SIT data showed that when overweight children are asked to give spontaneous explanations for an ambiguous situation, they report significantly more negative self-referent explanations (weight/shape and selfesteem) than normal-weight children. Both the negative weight/shape as well as negative self-esteem-related explanations were significantly more often reported by the overweight children than by the normal-weight children. An overweight child, for example, said that he was not chosen for the ball game (situation 2) because children do not like to play with a fat boy (being a negative weight/shape interpretation) and another one said that others did not chose him because he is not a good ball player (being a negative self-esteem explanation). A normalweight child reported that she was chosen because she is a very good ball player (positive self-esteem explanation).

Positive self-referent responses (weight/shape and self-esteem) were significantly less frequently reported by the overweight children. Although there was no difference in the number of positive weight/shape-related explanations between overweight and normal-weight children, the overweight children reported significantly fewer positive self-esteem-related explanations than normal-weight children. Further, the overweight children reported significantly fewer nonself-referent explanations than the normal-weight children.

Four backward regression analyses were then carried out, to test the relative contribution of gender, BMI, restraint and self-esteem (both global self-worth and self-perceived competence in the physical appearance domain) to the responses in the open-format SIT. The number and type of responses in the 
open-format SIT were the dependent variables (weight/shape positive, weight/ shape negative, self-esteem positive and self-esteem negative), and the relative contributions of gender, BMI, restraint and self-esteem were determined by entering gender, BMI, the EDE restraint score, the Harter self-perceived competence in the physical appearance domain and the Harter global selfworth subscale score as independent variables in the first model. The criterion to remove a variable was $10 \%$ (significance level $\geq 0.10$ ). The first backward regression analysis with the negative weight/shape responses as the dependent variable showed that BMI was the only and unique significant predictor of the weight/shape negative responses in the open-format SIT $\left(\beta=0.6, R^{2}=0.36\right.$, $p<0.001)$. The second backward regression analysis with the positive weight/shape responses as the dependent variable excluded all predictor variables, so the model did not include any significant contributor to positive weight/shape interpretations. The third backward regression analysis with the negative selfesteem responses as the dependent variable showed that the EDE restraint score was the only and unique significant predictor of negative self-esteem interpretations in the open-format SIT $\left(\beta=0.56, R^{2}=0.32, p<0.001\right)$. The final backward regression analysis with the positive self-esteem responses as the dependent variable showed that BMI was a unique predictor of positive self-esteem interpretations in the open-format SIT $\left(\beta=-0.50, R^{2}=0.25, p=0.002\right)$, indicating that a lower BMI predicted more positive self-esteem interpretations in ambiguous situations. Gender and the two types of self-esteem were no significant predictors in any of the models.

In sum, BMI explained most of the variance in both the negative weight/shape interpretations and positive self-esteem interpretations: a higher BMI was the only and a powerful predictor of an increasing amount of negative weight/shape interpretations and less positive self-esteem interpretations. Positive weight/shape responses were not predicted by any of the variables that entered the analyses. Negative self-esteem interpretations were predicted by the restraint score: more intentions to diet were related to more negative self-esteem interpretations.

Hypothesis 2: Overweight children will judge weight/shape and self-esteem to be more likely explanations for events with a negative outcome than normal-weight children. The forced-choice responses were scored on a three point scale, 1 for the most likely answer, 3 for the most unlikely answer and 2 for in between. The positions of the weight/shape and self-esteem explanations were determined for both the overweight and normal-weight group and differences in ranking were tested with the Mann-Whitney test. Table IV shows that the overweight children reported significantly more often weight/shape to be a more likely explanation for negative events than normal-weight children. Interestingly, self-esteem was considered to be a more likely explanation for negative events by the normalweight children. Weight/shape explanations were the most likely explanations for the overweight children and the most unlikely explanations for the normal-weight children. There were no differences in the likelihood of neutral explanations between both groups. 
Table IV. The forced-choice SIT: mean position of weight/shape, self-esteem and neutral explanations for negative situations $(1=$ most likely, $3=$ least likely $)$.

\begin{tabular}{lcccc}
\hline & Overweight $(n=20)$ & Normal-weight $(n=16)$ & & \\
& $M(S D)$ & $M(S D)$ & $\mathrm{Z}$ & $p$ \\
\hline Weight/shape & $1.8(0.4)$ & $2.3(0.3)$ & 3.3 & 0.001 \\
Self-esteem & $1.9(0.3)$ & $1.6(0.3)$ & 2.7 & 0.006 \\
Neutral & $2.3(0.3)$ & $2.1(0.5)$ & 0.75 & 0.452 \\
\hline
\end{tabular}

Table V. The estimated likelihood (probability) that negative weight/shape-related events occur, the expected degree of badness (subjective costs) of the events and its threat value (probability $\times$ costs).

\begin{tabular}{lcccc}
\hline & Overweight $(n=20)$ & Normal-weight $(n=16)$ & & \\
& $M(S D)$ & $M(S D)$ & $t(34)$ & $p$ \\
\hline Probability & $2.8(0.9)$ & $2.2(0.3)$ & 2.9 & 0.007 \\
Subjective costs & $3.3(1.0)$ & $2.9(0.7)$ & 1.4 & 0.164 \\
Threat value (probability $\times$ costs) & $9.4(4.1)$ & $6.3(1.8)$ & 2.8 & 0.007 \\
\hline
\end{tabular}

Hypothesis 3: (a) Overweight children will overestimate the likelihood of negative weight/ shape-related events to occur compared to normal-weight children, and they rate the occurrence of such events as more costly than normal-weight children. (b) Overweight children will show an increased threat perception. The overweight children estimated the probability that negative weight/shape-related events occur significantly larger than normal-weight children (Table V). The estimated costs were however not different between groups, meaning that if it happens, both groups expect it to be equally bad. A threat perception score was calculated by multiplying the probability and costs ratings. The threat perception was significantly higher for the overweight children compared to the normal-weight children.

\section{Discussion}

The present study shows that overweight children report more negative body weight/shape explanations as well as more negative and less positive selfesteem-related explanations for ambiguous events than normal-weight children. Also in negative situations, negative weight/shape explanations were more likely for the overweight children than for the normal-weight ones. Surprisingly, in these negative situations general self-esteem was a more likely explanation for the normal-weight children. Finally, the overweight children overestimated the probability that negative weight/shape-related events would occur compared to normal-weight children, whereas the costs when happening were equal for 
both groups. The threat perception (probability $\times$ costs) was significantly larger for overweight children than for normal-weight children.

BMI explained most of the variance in both the number of negative weight/ shape interpretations and the number of positive self-esteem interpretations: a higher BMI was the only and powerful predictor of an increasing number of negative weight/shape interpretations and fewer positive self-esteem interpretations. The misinterpretation of neutral situations in terms of body weight/shape is called an interpretation bias but such a bias might stem from reality. Cognitive theory states that negative experiences are the source of interpretation biases (Taylor \& Alden, 2005). Overweight children may have actually experienced a greater number of situations in which weight and shape have been a main reason for a negative outcome than normal-weight children. Frequent and repeated negative incidents concerning body weight/shape, e.g. teasing, might thus make children vulnerable to the development of interpretation and judgment biases, the latter leading to an overestimation of the probability of happening.

Overweight children are thus more likely to endorse a negative body-weight/ shape-related interpretation of neutral and negative events. Earlier studies have shown that overweight children show selective attention to appearance cues (Braet \& Crombez, 2003). Both the interpretation bias and attentional bias flow from underlying knowledge structures (schemas) that filter information and direct what a subject attends to, they guide attention to, memory for and interpretation of stimuli, in ways that serve to maintain the behaviour (Hargreaves \& Tiggemann, 2002; Viken, Treat, Nosofsky, McFall, \& Palmeri, 2002). Both biases show that overweight children prioritise and amplify weight/shape stimuli while other stimuli are inhibited, thereby making themselves more vulnerable to biased thinking and body distress.

Of particular interest is the finding that negative self-esteem interpretations were predicted by (only the) restraint scores: it was found that more intentions to diet were related to generating more negative self-esteem interpretations in the free-format test. Increasing restraint scores as measured with the EDE are not indicating that one successfully restrains his food intake; more often it is a sign of unsuccessful attempts to reduce intake. Circumstantial evidence for the idea that high restraint in this sample is related to unsuccessful diet attempts is provided by the high positive correlation between BMI and EDE restraint, $r=0.64, p<0.001$, meaning that higher $\mathrm{BMI}$ is related to increased restraint scores. The data indicate that more frequent but unsuccessful diet attempts increase the number of negative interpretations of ambiguous situations in terms of self-esteem. Being unsuccessful in dieting might lower self-esteem in young overweight children.

The increased vulnerability to interpretation and attention biases in overweight children emphasises the need to use strategies that tackle further development of distortions in information processing. More specifically, cognitive techniques may address the overestimation - made by overweight children - of the chance that any bad situation will happen and the seriousness of the consequences in case such a situation would indeed take place. Surprisingly, research has rarely 
addressed the role of cognitive processes in the maintenance of child obesity. Therapists may help children challenge irrational beliefs and replace them by more rational alternatives. For example, an overweight child may believe that, due to his corpulence, he is not a likeable person. By using the cognitive technique called "multidimensional scaling", the child may discover that selfesteem consists of more dimensions than body weight/shape only. During multidimensional scaling of the aforementioned assumption, the child is asked to think of a person who is very likeable and a person who is not. Both names are written on a whiteboard and also put on a $100 \mathrm{~mm}$ visual analogue scale (with the end points "not at all likeable" and "extremely likeable"). It is important that both persons represent the extremes of the scale. Next, the child names all qualities that make the likeable person likeable and all characteristics that make the unlikeable person unlikeable. The therapist helps when important qualities seem to be forgotten. These qualities are written under the respective names whereafter both persons are rated with respect to all qualities on a 10-point scale. When "corpulence"or "being slender" is not part of these qualities, this is noted by the therapist, whereafter the child may decide whether this quality should be included. Then, the child rates himself on all named qualities, as well. Finally, for all three persons a mean "likeability score" is calculated. It is very likely that the "extremely likeable person" does not reach the maximum score (10) and the unlikeable person probably does not reach the minimum score (0). It is also very likely that the child himself scores a lot more than zero, in our experience this is often more than 50. The final step is to put the two persons' names as well as the child's name on the point of the VAS (Visual Analogue Scale) where they belong after calculating their scores. The therapist then asks the child what can be noticed in this example; it should be clear that extremely likeable persons are no angels and unlikeable persons are no devils. But most importantly, it strikes the child that he scores a lot higher on likeability than he thought before, which is due to the fact that likeability consists of a lot more than being thin.

A full-blown cognitive bias is quite pervasive and may influence many of the cognitive, emotional and behavioral reactions of the overweight child. Taken together, it might be a rewarding enterprise to use cognitive interventions in the early treatment of overweight children to prevent (further) development of cognitive biases such as the interpretation bias.

\section{References}

Amir, N., Foa, E. B., \& Coles, M. (1998). Social phobic's evaluation of ambiguous situations. Behaviour Research and Therapy, 36, 945-957.

Amir, N., Beard, C., \& Bower, E. (2005). Interpretation bias and social anxiety. Cognitive Therapy and Research, 29, 433-443.

Barrett, P. M., Dadds, M. R., \& Rapee, R. M. (1996). Family treatment of childhood anxiety: A controlled trial. Fournal of Consulting and Clinical Psychology, 64, 333-342. 
Braet, C., \& Crombez, G. (2003). Cognitive interference due to food cues in childhood obesity. fournal of Clinical Child and Adolescent Psychology, 32, 32-39.

Bryant-Waugh, R. J., Cooper, P. J., Taylor, C. L., \& Lask, B. D. (1996). The use of the eating disorder examination with children: A pilot study. International fournal of Eating Disorders, 19, 391-397.

Cooper, M. J. (1997). Bias in interpretation of ambiguous scenarios in eating disorders. Behaviour Research and Therapy, 35, 619-626.

Cooper, M. J., Wells, A., \& Todd, G. (2004). A cognitive model of bulimia nervosa. British fournal of Clinical Psychology, 43, 1-16.

Decaluwé, V., \& Braet, C. (1999). Dutch translation of the Child Eating Disorder Examination, authored by C. G. Fairburn, Z. Cooper, and R. Bryant-Waugh. Ghent University: Unpublished manuscript.

Decaluwé, V., \& Braet, C. (2004). Assessment of eating disorder psychopathology in obese children and adolescents: Interview versus self-report questionnaire. Behaviour Research and Therapy, 42, 799-811.

Decaluwé, V., Braet, C., \& Fairburn, C. G. (2003). Binge eating in obese children and adolescents. International fournal of Eating Disorders, 33, 78-84.

Dietz, W. H. (1995). Childhood obesity: Prevalence and effects. In K. D. Brownell \& C. G. Fairburn (Eds), Eating disorders and obesity: A comprehensive handbook. New York \& London: The Guilford Press.

Dobson, K. S., \& Dozois, D. J. A. (2004). Attentional biases in eating disorders: A meta-analytic review of Stroop performance. Clinical Psychology Review, 23, 1001-1022.

Epstein, L. H., Valoski, A., Wing, R. R, \& McCurley, J. (1994). Ten year outcomes of behavioral family-based treatment for childhood obesity. Health Psychology, 13, 373-383.

Fairburn, C. G., \& Cooper, Z. (1993). The Eating Disorder Examination. In C. G. Fairburn \& G. T. Wilson (Eds), Binge eating: Nature, assessment, and treatment (12th ed., pp. 317-360). New York: Guilford Press.

Foa, E. B., Franklin, M. E., Perry, K. J., \& Herbert, J. D. (1996). Cognitive biases in generalized social phobia. Fournal of Abnormal Psychology, 105, 433-439.

Grilo, C. M., Wilfley, D. E., Brownell, K. D., \& Rodin, J. (1994). Teasing, body image and self-esteem in a clinical sample of obese women. Addictive Behaviors, 19, 443-450.

Hargreaves, D., \& Tiggemann, M. (2002). The role of appearance schematicity in the development of adolescent body dissatisfaction. Cognitive Therapy and Research, 26, 691-700.

Harter, S. (1985). Manual for the self-perception profile for children. Denver: University of Denver.

Hill, A. J., \& Williams, J. (1998). Psychological health in a non-clinical sample of obese women. International fournal of Obesity, 22, 578-583.

Lee, M., \& Shafran, R. (2004). Information processing biases in eating disorders. Clinical Psychology Review, 24, 215-238.

Mathews, A., \& Mackintosh, B. (2000). Induced emotional interpretation bias and anxiety. Fournal of Abnormal Psychology, 109, 602-615.

Muris, P., \& Mayer, B. (2000). Vroegtijdige behandeling van angststoornissen bij kinderen (Early treatment of anxiety disorders in children). Gedrag E Gezondheid, 28, 235-242.

Nauta, H., Hospers, H., \& Jansen, A. (2001a). One-year follow-up effects of two obesity treatments on psychological well-being and weight. British fournal of Health Psychology, 6, 271-284.

Nauta, H., Hospers, H., Jansen, A., \& Kok, G. (2000). Cognitions in obese binge eaters and obese non-binge eaters. Cognitive Therapy and Research, 24, 521-531.

Nauta, H., Hospers, H., Kok, G., \& Jansen, A. (2001b). A comparison between a cognitive and a behavioral treatment for obese binge eaters and obese non-binge eaters. Behavior Therapy, $31,441-461$.

Pierce, J. W., \& Wardle, J. (1997). Cause and effect beliefs and self-esteem of overweight children. Fournal of Child Psychology and Psychiatry and Allied Disciplines, 38, 645-650.

Roede, M., \& van Wieringen, J. (1985). Growth diagrams 1980. Netherlands third nation-wide survey. Tijdschrift voor Sociale Gezondheidszorg, 63(Suppl), 1-34. 


\section{4}

A. Fansen et al.

Taylor, C. T., \& Alden, L. E. (2005). Social interpretation bias and generalized social phobia: The influence of developmental experiences. Behaviour Research and Therapy, 43, 759-777.

Veerman, J. W., Straathof, M. A. E., Treffers, A., Van den Bergh, B. R. H., \& Ten Brink, L. T. (1997). Competentiebelevingsschaal voor kinderen. Lisse: Swets \& Zeitlinger.

Viken, R. J., Treat, T. A., Nosofsky, R. M., McFall, R. M., \& Palmeri, T. J. (2002). Modeling individual differences in perceptual and attentional processes related to bulimic symptoms. fournal of Abnormal Psychology, 111, 598-609.

Voncken, M. J., Bögels, S. M., \& de Vries, K (2003). Interpretation and judgmental biases in social phobia. Behaviour Research and Therapy, 41, 1481-1488.

Wardle, J., Waller, J., \& Fox, E. (2002). Age of onset and body dissatisfaction in obesity. Addictive Behaviors, 27, 561-573.

Warren, R., Zgourides, G., \& Jones, A. (1989). Cognitive bias and irrational belief as predictors of avoidance. Behaviour Research and Therapy, 27, 181-188.

Williamson, D. A., Muller, S. L., Reas, D. L., \& Thaw, J. M. (1999). Cognitive bias in eating disorders: Implications for theory and treatment. Behavior Modification, 23, 556-577.

Wilson, G. T. (1994). Behavioral treatment of childhood obesity: Theoretical and practical implications. Health Psychology, 13, 371-372.

Wilson, G. T. (1996). Acceptance and change in the treatment of eating disorders and obesity. Behavior Therapy, 27, 417-439. 